\title{
COMPARISON OF GNSS SYSTEMS
}

\section{SEDLAR M.}

Abstract: The chapter deals with introducing and a comparison of known GNSS systems. It introducing systems by summarizing of their segments, abilities, services, used frequencies and accuracy. It also looks to the future of each of systems and introduce options and benefits of combining systems.

Key words: GNSS, NAVSTAR, GPS, GLONASS, GALILEO
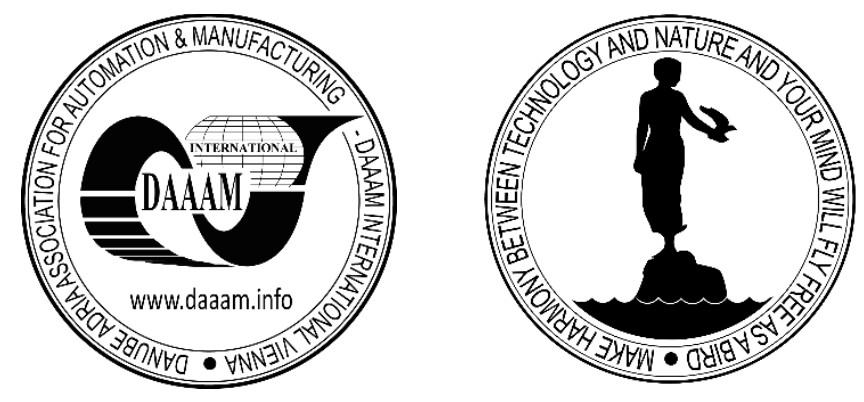

Authors' data: Ing. Sedlar M[artin], *Tomas Bata University in Zlin Faculty of Applied Informatics, Nad Stranemi 4511, 760 05, Zlín, Czech Republic, marty.sedlar@gmail.com

This Publication has to be referred as: Sedlar, M[artin] (2017). Comparison of GNSS Systems, Chapter 17 in DAAAM International Scientific Book 2017, pp.217226, B. Katalinic (Ed.), Published by DAAAM International, ISBN 978-3-902734-129, ISSN 1726-9687, Vienna, Austria

DOI: $10.2507 /$ daaam.scibook.2017.17 


\section{Introduction}

GNSS stands from the English term "Global Navigation Satellite System,". In this article we will focus on the four most famous and also the most important systems of this kind. It is well known the American NAVSTAR GPS, European system GALILEO, GLONASS from Russia and finally the Chinese COMPASS (Beidou II). All these systems are still actively developed and their capabilities and accuracy are improved over time.

\section{NAVSTAR GPS}

NAVSTAR (Navigation Signal Timing and Ranging Global Positioning System), operated by the Ministry of Defense of the USA. It was founded in 1973 by merge of two projects, their names was System 621B (USAF) and Timalon (US Navy). Between 1978 and 1985 has been launched first 11 satellites of Block I as a space segment of navigation system. Despite the fact that the system was originally designed only for 24 satellites, this day (7.2015) there are 32 satellites, of which it is 31 are fully operational and one, namely satellite USA-203, is in reserve for the case of failure of any satellite.

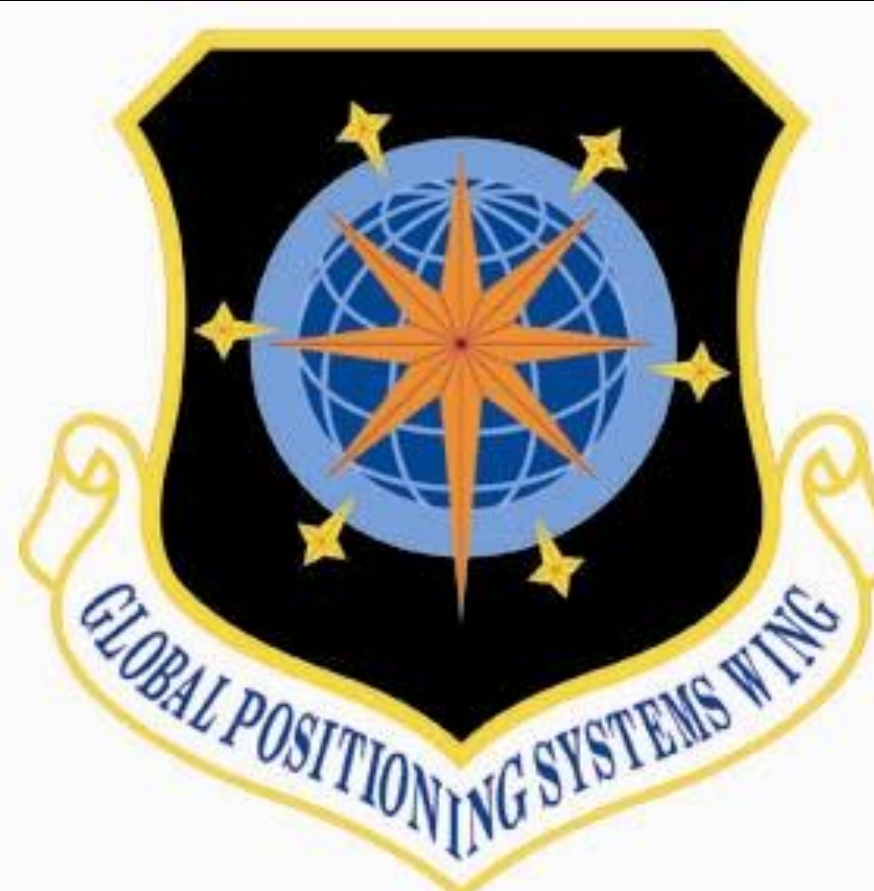

Fig. 1. Global Positioning Systems Wing logo.

\subsection{Space segment}

It is a system of 32 satellites orbiting at 6 circular trajectories at an altitude of 20,350 $\mathrm{km}$ above the earth's surface. The orbits are relatively displaced by $60^{\circ}$ and are at an inclination of $55^{\circ}$. Satellite circulation period is $11 \mathrm{~h} 58 \mathrm{~min}$. The number of 32 satellites operating in system reach its limit, because the data frame for numerical identification of satellites has only 5 bits. 


\subsection{Control Segment}

This part of the system has the main task of monitoring and maintaining the system. Managing necessary maneuvers of satellites, doing correction of atomic clocks, calculates efemedrid prediction (predicted satellites trajectory) and data collection for the ionosphere model.

Control segment consists of the Navstar headquarters in Los Angeles, California, the control center in Colorado Springs, 3 command stations and 18 monitoring stations. If the Control segment disrupted or destroyed for any reason, the NAVSTAR system is able to automatically switch to mode "AUTONAV". In this mode it is able to operate up to 6 months without control intervention. But Such a scenario, never happened.

\subsection{User Segment}

User segment provides GPS satellite signals receivers within its range. Based on data from these signals, which contain the known position of the satellites and the timestamp of each satellites, the receiver calculates its own position. The data is transmitting only to the user's workstation, no backwards. So NAVSTAR provides the following services to users:

- Standard Positionning Service (SPS) - this service uses only L1 frequency $(1575.42 \mathrm{MHz})$. This service is limited for $515 \mathrm{~m} / \mathrm{ps}$ of the receiver speed and a maximum height of receiver is $18 \mathrm{~km}$, all for safety reasons. Usage is aimed at the civilian sector.

- Precise Positioning Service (PPS) - the encrypted service of the system, which thanks to the use more frequencies offers precise orientation in space. Service is used primary in the army and the aviation sector.

\subsection{Future of NAVSTAR GPS}

American system NAVSTAR expects several changes and improvements in next few years. These changes are necessary now because the life of some parts of the system, mainly space segment is very limited and must be replaced.

Since 2016 NAVSTAR agency wants to launch a new type of satellites called GPS III, which will bring improved navigational accuracy and the longest life of the satellites from the current 10 years to 15 years.

Another improvements belongs to the Control segment, which is by schedule during 2018 should enter the OCX mode, which offers several improvements, such as support for civilian control signal L2C, L5 and L1C. Another improvement will be full support of the management the new generation of GPS III satellites. OCX mode has been developed since 2008 in cooperation with the Raytheon company.

\section{GLONASS}

GLONASS (Globalnaja navigacionnaja sputnikovaja Sistema) is a system developed by the Soviet Union and now operated by the Russian army. Yet it is still not well known as its competitor from the US, it is the world's second most used GNSS. 
The system is developing since 1976 and its first test satellite was successfully launched in 1982. The following three years was launched another 9 satellites, which concluded the first block of satellites called Uragan1. One of the main differences from the NAVSTAR system is the life of the satellites. By the year 2014 was for GLONASS system launched 132 satellite, but only 28 operational satellites was remained operational. Four these satellites is used as backup in case of failure of some of the units.

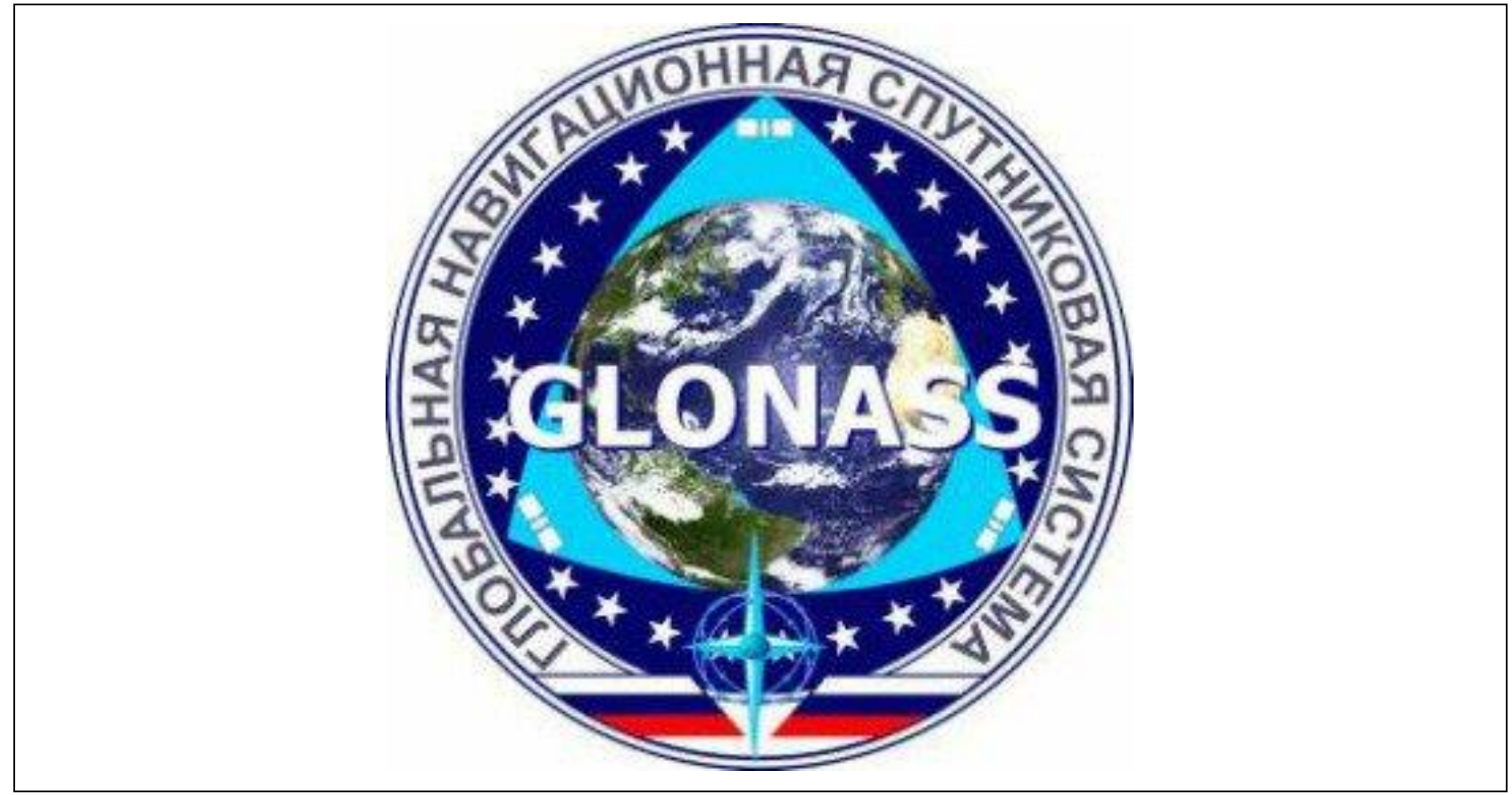

Fig. 2. GLONASS

\subsection{Space segment}

Space segment consists 24 operational satellites rotating only in three orbits around the earth. In each orbit is 8 symmetrically spaced satellites in intervals $45^{\circ}$ each other. Satellites have $19100 \mathrm{~km}$ altitude above the earth's surface and they are relatively displaced by $120^{\circ}$. Circulation height is lower than the NAVSTA's, so the circulation time is slightly shorter at $11 \mathrm{~h} 15 \mathrm{~min}$.

\subsection{Control segment}

The ground segment have responsibility for monitoring and maneuvering satellites, doing maintenance atomic clock, synchronization and making reports of the state of the navigation system every few hours. The segment is entire on the territory of the Russian Federation, which implies that it is not possible to monitor entire space segment at same time. The control segment consists of a control center in Krasnoznamensk SCC, 3 advanced stations in Selkovo, Jenisersku and in Komsomolsk. 5 Furthermore, command stations is located in St. Petersburg, Ussurisku, Selkovo, Yeniseinia and Konsomolsku. And finally, 10 monitoring stations distributed over the territory of Russia. 


\subsection{User segment}

Here, as same as the NAVSTAR, user stations receiving signals from the satellites, which is in its range and use them to determine its location. The more satellite signals be able to station receive, the better determined its location. But for fundamental function receiver needs at least 4 satellites in range. Positioning then extend three levels of users:

- Standard Positioning (SP) - civilian service with lower accuracy, which provides GLONASS free of charge since 2007.

- High Positioning (HP) - Service to authorized users. This is mainly in use of the Russian army and some selected government institutions.

- Search and Rescue (SAR) - this service is part of an emergency localization services COSPAS/SARSAT, which is a global satellite network for emergency services with the possibility of two-way communication between satellites and receiver.

\subsection{Future of GLONASS}

The most important modernization of the GLONASS system will be mainly commissioning of new generation satellites GLONASS-K2, which increases the life of satellites for more than 10 years. Another upgrade will be addition of CDMA band. And in 2020, the developers promise to increase the accuracy of GLONASS system. Unfortunately GLONASS does not reach the precision of competing NAVSTAR GPS. But after full upgrade some promises speak about increase accuracy to $\pm 6 \mathrm{~cm}$.

\section{GALILEO}

Galileo is Europe's independent navigation system, which became the answer to competing projects NAVSTAR, GLONASS, or Baidou (COMPASS). Before the GALILEO was came none of the EU member countries have a similar system under their control.

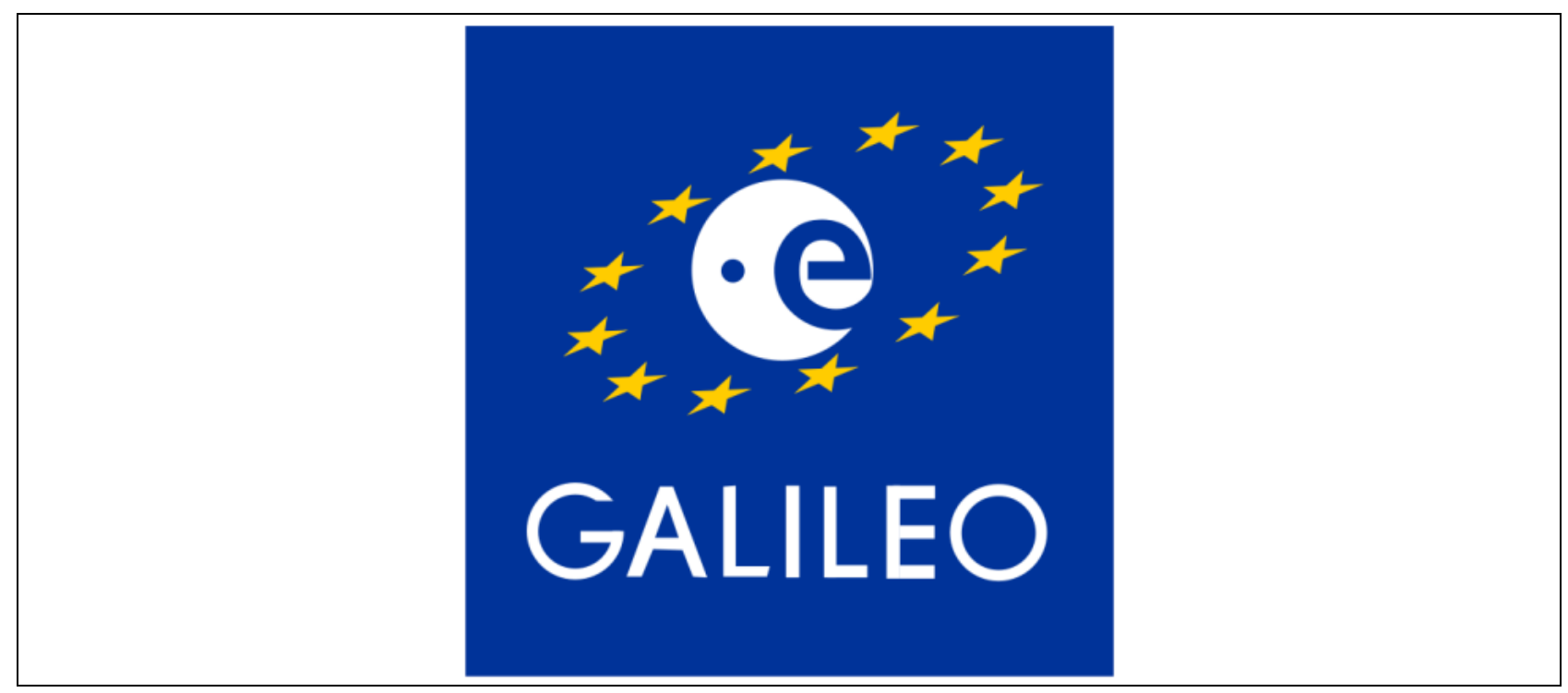

Fig. 3. GALILEO 
The beginning of the Galileo project dates back to 1999, when it originated a plan to build a new independent GNSS for Europe. Project starts with a budget of 5 billion EURO funded from private sources. Later, the project took by Europe Union, and since 2004 have been built administrative center in Brussels and subsequently the technology center of project in Oberpfaffenhofen near Munich. Development was given charge of the European Space Agency ESA in the Netherlands. In 2005 was sent into orbit the first test satellite named Giove-A. Between years 2008 and 2012, was launched into space next 5 satellites and March 12, 2013 was carried out the first test focus targets on the earth's surface with an accuracy of less than 15 meters.

The first positioning services that have been planned already in 2014, but due to failure of the launcher in August 2014, two satellites have not received the proper orbit, and although managed one of mingle among half a year later stabilize, corrections second satellite lasts until today (6.2015). The progress of construction of the system is thus greatly slowed and the most optimistic promises about the operational capability talks about the turn of the years 2019/2020.

\subsection{Space segment}

At the time when this article was written a space segment was still under construction and only 4 satellites was in operation status. Another 4 satellites were successfully launched lately and they were in preparation for operation capability and one was lost for a power failure.

For the full operation capability, the system requires 30 operational satellites in 3 orbits in mutual displacement of $120^{\circ}$. Each trajectory will have a 9 satellites into full operation and one satellite as backup in case of failure. The satellites orbit is at an altitude $23,222 \mathrm{~km}$ with inclination of $56^{\circ}$ relative to the ground.

\subsection{Control segment}

This is a ground segment, which is located in two control centers, in Fucino in Italy and in Munich Germany. Each of these stations are able to take control of the entire system in case of loss of one of the stations.

The control segment takes on a correction of satellite orbits and maintaining the operability of the entire system and from obtained data created report of the state of the system. Control stations augmented by 20 monitoring stations, which are located all throughout the world.

\subsection{User segment}

There is a bigger difference and advantage of Galileo over other GNSS systems, and that advantage is the number of types of user services, which is able to provide.

- Open Service (OS) - OS will be available for the general public, and its accuracy will move on the border of 4 meters horizontally and 8 meters in the vertical plane. 
- Commercial Service (CS) - encoded a paid service that will provide greater positional accuracy than the OS.

- Safety of Life Service (SLS) - SLS is a highly secure service with regards to data integrity. For its high reliability is usable for air traffic control and the like for example.

- Search and Rescue (SAR) - even GALILEO is connected to a worldwide network COSPAS / SARSAT to support the rescue system.

- Public Regulated Service (PRS) - encrypted service for the security of the states. Mostly for military use.

\subsection{Future of Galileo}

Due to the fact that Galileo is currently under construction, and commissioning is the music of the future, it will be the biggest success of its introduction to the full operational status. If everything goes according to the plan, we will be able to navigate by Galileo since 2020 and it will be capable of accuracy to less than one meter in CS, which will by is great.

\section{BEIDOU-2 (COMPASS)}

It is another independent GNSS satellite, but this time under the authority of the Chinese People's Republic. Its name is Beidou. Beidou is the Chinese name for the constellation Ursa Major, which has a system in the official logo.

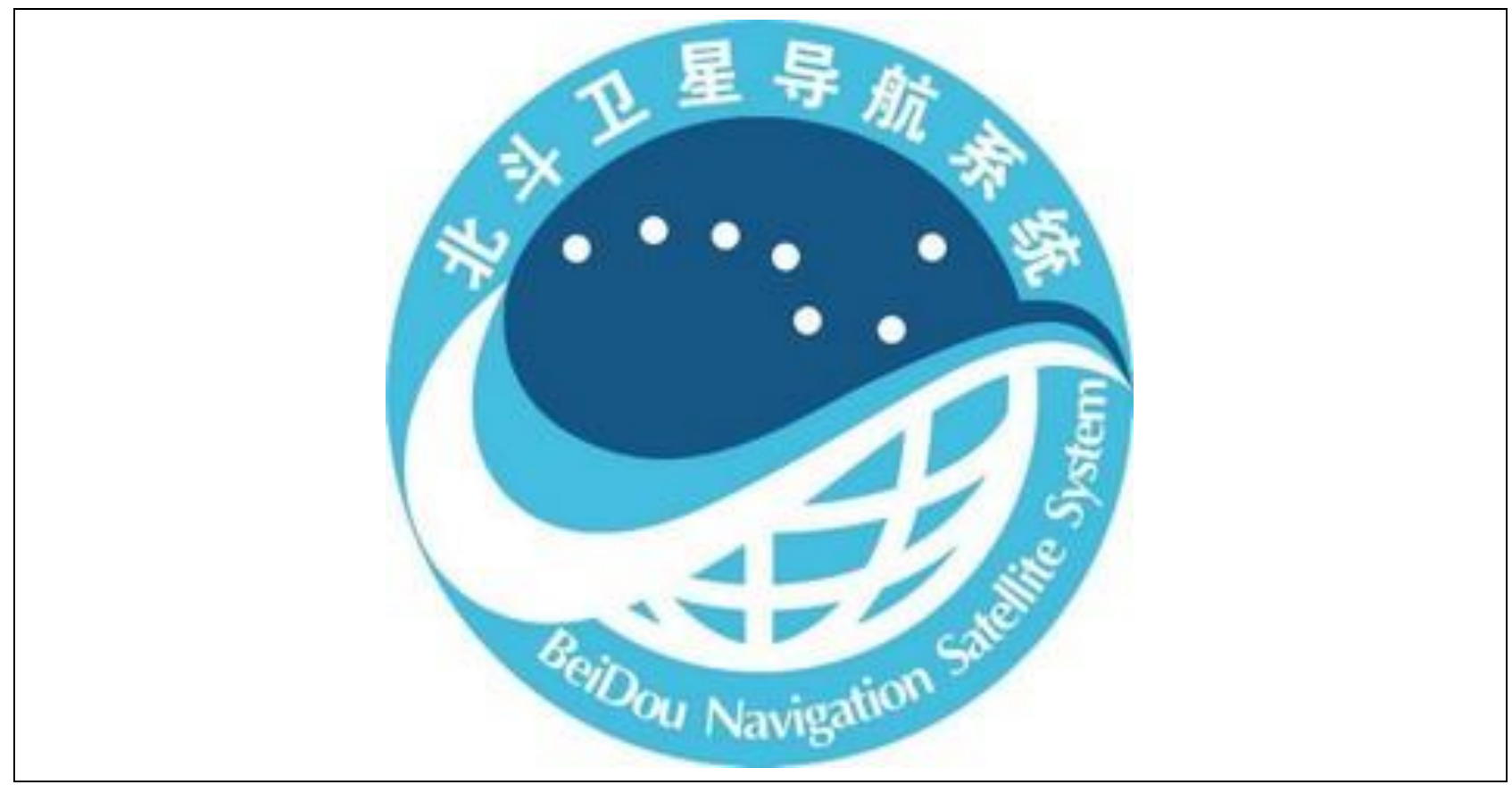

Fig. 4. BEIDOU-2

Beidou became the fourth GNSS system, whose development was outstripped even its competitor European Galileo project. History of Chinese GNSS begun in 1997, when the project started. The first three satellites were successfully launched between years 2000 and 2003, which were placed in geostationary orbit and these was running 
only as a local navigation system over in China. In 2004 came the decision to extend Beidou into global scale. Since 2007, the system was upgraded and the second generation called Beidou-2 was launched. Beidou-2 has been designed for global use. For better globalization system gets new name, COMPASS. Both systems Beidou-1 and Beidou-2 (COMPASS) simultaneously running until 2012, then the Beidou-1 finally shut down. Since 2007, it was launched another 20 satellites for the Beidou-2 system (07.2015).

\subsection{Space Segment}

Space segment of Beidou-2 is designed for 27 satellites in three orbits plus 3 backup satellites (one for each orbit). Trajectories are placed to a height of $21,500 \mathrm{~km}$, they are offset by $120^{\circ}$ and in an inclination of $55.2^{\circ}$. Another part of space segment is 5 satellites in geostationary orbit, which will cover the entire surface of the planet and increasing accuracy. The final number of operational satellites operating at full capacity supposed to be 35 .

\subsection{Control Segment}

First is a Control station which is in charge of monitoring satellites, process measurement stations and generation of navigation management. Another part is Uploading Stations. This stations has the task of uploading the correction data and navigation satellites. System has only 2 Uploading. Third and last part of control ground segment is monitoring stations. Stations collected an information from satellites and forwarded to the Control station. Monitoring stations are deployed 30 over the China.

\subsection{User Segment}

There will be a system Beidou/COMPASS offer only two services:

- Open services (OS) - OS is open civilian and navigation platform open to the general public with an accuracy of up to $10 \mathrm{~m}$ positioning and up to $0.2 \mathrm{~m} / \mathrm{s}$ velocity.

- Limited Service (LS) - encrypted service designed for military purposes, which increases the accuracy compared with the Open Service, but exact accuracy is not yet known.

\subsection{Future of Beidou}

Full operational capability of the system is planned, as well as the European Galileo to 2020 .

\section{Conclusion}

In conclusion we can say that position determination of the receiver side are all the current GNSS systems are nearly identical. Their differences are mainly in accuracy, but everyone is trying to make the best possible result. 


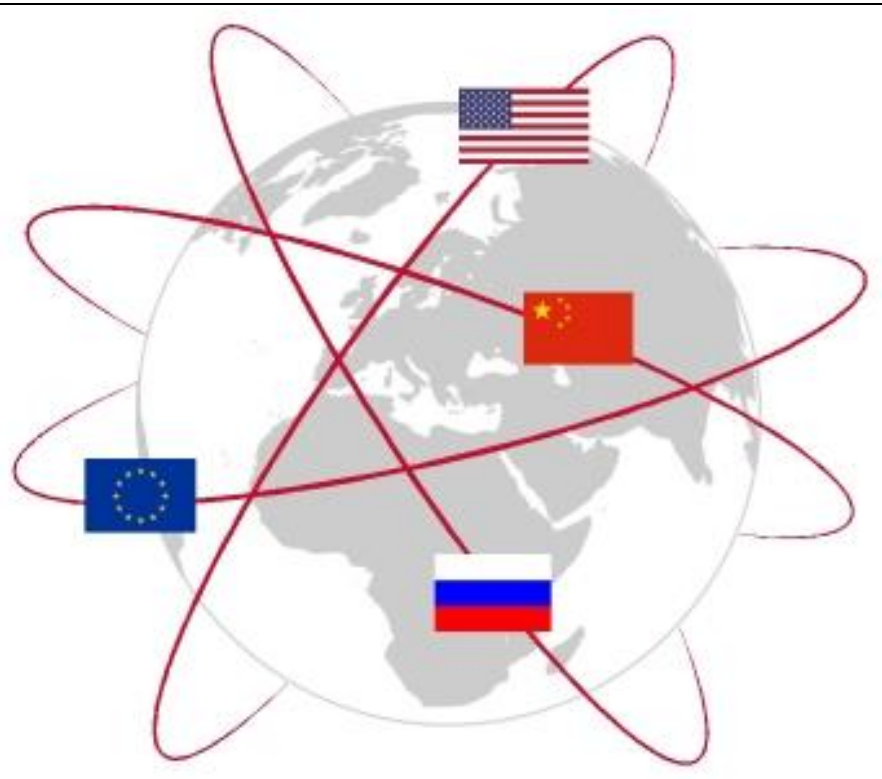

Fig. 5. Independent competitive system

Services, which provide the systems are up GALILEO, which partly extends these capabilities, also the same to. The only reason why each of the major world's trying build their own independent GNSS under its own administration, remains purely an effort to gain independence from the competitive system.

\begin{tabular}{|c|c|c|c|l|l|}
\hline Name & $\begin{array}{c}\text { Num. of } \\
\text { trajectories }\end{array}$ & $\begin{array}{c}\text { Num. of } \\
\text { Satellites }\end{array}$ & $\begin{array}{c}\text { Altitude } \\
{[\mathbf{k m}]}\end{array}$ & \multicolumn{1}{|c|}{ Services } & \multicolumn{1}{c|}{ Frekvencies } \\
\hline NAVSTAR GPS & 6 & 32 & 20350 & $\begin{array}{l}\text { Standart Positioning } \\
\text { Precise Positioning }\end{array}$ & $\begin{array}{l}\text { L1 - 1563-1587 MHz } \\
\text { L2 - 1215-1237 MHz } \\
\text { L3 - 1381.05 MHz } \\
\text { L4 - 1379.913 MHz } \\
\text { L5 - 1164- 1191.795 MHz }\end{array}$ \\
\hline GLONASS & 3 & 28 & 19100 & $\begin{array}{l}\text { Standart Positionning } \\
\text { Hight positionning } \\
\text { Search and Rescue }\end{array}$ & $\begin{array}{l}\text { G1 - 1593-1610 MHz } \\
\text { G2 - 1237-1260 MHz } \\
\text { G5 - 1191.795- 1214 MHz }\end{array}$ \\
\hline GALILEO & 3 & 30 & 23222 & $\begin{array}{l}\text { Open Service } \\
\text { Commercial Service } \\
\text { Safety of Life Service } \\
\text { Search and Rescue } \\
\text { Public Regulated Service }\end{array}$ & $\begin{array}{l}\text { E1 - 1559-1610 MHz } \\
\text { SAR - 1544-1545 MHz } \\
\text { E5a - 1164-1191.795 MHz } \\
\text { E5b - 1191.795-1214MHz } \\
\text { E6 - 1260-1300 MHz }\end{array}$ \\
\hline BEIDOU-2 & 3 & 35 & 21500 & $\begin{array}{l}\text { Open Service } \\
\text { Limited Service }\end{array}$ & $\begin{array}{l}\text { B1 - 1561.098-1589.742 } \\
\text { MHz } \\
\text { B2 - 1207.14 MHz } \\
\text { B3 - 1268.52 MHz } \\
\text { L5 - 1176.45 MHz }\end{array}$ \\
\hline
\end{tabular}

Tab 1.- GNSS Facts

In practice, the use of dual receivers that combine the possibilities of NAVSTAR and GLONASS. These receivers can achieve better accuracy than each system separately, 
mainly due for the number of satellites in range simultaneously. In simple terms we can say, two are better than one. Already, some modern receivers include support for Galileo and COMPASS to, though neither of them is far from complete.

\section{References}

Howell, Elizabath. Navstar: GPS Satellite Network. Space.com [online]. 2013. Available from: http://www.space.com/19794-navstar.html [online]. Accesed on: 2015-10-2.

http://www.gps.gov/ - Official U.S. Government information about the Global Positioning System (GPS) and related topics (2015) [online]., Accesed on: 2015-9-25. http://www.navipedia.net/- The reference for Global Navigation Satellite Systems (2015), Accesed on: 2015-10-3.

http://www.czechspaceportal.cz/- The Czech Space Portal - Information webpage of The Coordination Council of ministry of Traffic and space activities (2015) [online]. Accesed on: 2015-10-10.

El-Rabbany, Ahmed. Introduction to GPS: The Global Positioning System. 1. Boston: Artech House, 2002. ISBN 1596930160.

Rapant, P.: Družicové polohové systémy. VŠB-TU Ostrava, 2002. 200 str. ISBN 80248-0124-8. Available from: http://gis.vsb.cz/dokumenty/dns-gps/at_download/file. 